\title{
A COMPARATIVE STUDY OF THE GEOMETRIC MOTIFS OF THE ATEEQ MOSQUE (SHIRAZ) AND THE CORDOBA MOSQUE (CORDOBA) WITH A CONTEXTUAL APPROACH
}

| Received August $7^{\text {th }}, 2020$ | Accepted September 11 1 th, 2020 | Available online December $15^{\text {th }}, 2020$ |

DOI http://dx. doi. org/10.18860/jia.v6i2. 10113

Somayeh Karimi

Department of Art Research, Faculty of Art, Central Tehran Branch, Islamic Azad University Tehran, Iran

\section{Parnaz Goodarzparvari \\ Department of Visual Communication, Faculty of Art, \\ Central Tehran Branch, Islamic Azad University \\ Tehran, Iran \\ Corresponding author: \\ E-mail: p.goodarzparvari@iauctb.ac.ir}

\section{Mohammad Aref}

Department of Theater, Faculty of Art,

Central Tehran Branch, Islamic Azad University

Tehran, Iran

Pardis Bahmani

Faculty of Art,

South Tehran Branch, Islamic Azad University

\begin{abstract}
Islamic art is an introverted art derived from mystical thought and believes expressed in artistic activities and is pure, indigenous, and commensurate with the spirit and socia status of its time; Islamic architecture also has an Islamic foundation, and it has a close relationship with the decorative arts. In this regard, mosques are considered the most significant Islamic architecture achievements; in most cases, geometrical shapes and motifs with religious and natural themes have been used. Therefore, the present study's mims with relicus and ntura the primary purpose is to study the geometric patterns of the Ateeq Mosque (Shiraz) and the collected data revealed that the motifs and their role in both the Ateeq Mosque of Shiraz and Cordoba are similar. Among the essential motifs observed in these two mosques can be the circle (symbol of being and the symbol of heaven and God), Shams (symbol of the sun and celestial light), the triangle with the downward vertex, the symbol of the female principle and the upward symbol of the mountain symbol and the masculine principle and crucifix (symbol of rotation of the seasons and permanent reproduction) and spiral as the symbol of fertility. In the Islamic period these motifs are docoted with architectural symbol therility. In the lslamic period, these mitectural tion of natural elements have been noticed, geometric motifs symbolically evoke those tion of natural elements have been noticed, geometric motifs
sacred elements and were illustrated in Iran and Spain's arts.
\end{abstract}

\section{KEYWORDS:}

Geometric motifs, Islamic architecture, Geometry, Ateeq Mosque (Shiraz), Cordoba Mosque

\section{INTRODUCTION}

Context-oriented architecture is an attempt to demonstrate the visual environment's potential on a larger scale than architecture. Contextual architecture generally addresses the need for a physical environment. Islamic architecture's global importance lies in constructing historical mosques, which possess a unique position due to its decorative motifs. These ornamental motifs are remnants of Islamic times representing the ideas, culture, and art of that period. Of course, these motifs have been in Iranian culture for thousands of years, and their beginnings go back to the pre-Islamic era. The Muslim artists have decorated mosques with a variety of animal, plant, and geometric ornamentation in Islamic buildings and have somehow positioned these ornaments as a means of expressing their religious and ritual beliefs. Their involvement with religious beliefs reflects a kind of immortality, originality, and purity in which the rooting of these motifs can lead to the minds of architects and thus to the culture and worldview and the glitter of ideals of those socie- ties. Among these unique and essential motifs are the geometric motifs, which are called Knots by the experts. These motifs have various textures of regular geometric shapes. Geometric shapes have long been used in various parts of mosques and religious sites, such as domes, porches, tiles, etc [1].

In the formation, evolution, and continuity of Islamic art and Islamic architecture, Iranians' contributions to other Islamic art artists such as Mesopotamia, Syria, and Egypt were more significant [2]. The architecture of mosques has survived over the centuries as Islamic decorative arts have grown, and there is no doubt that the high value and richness of decorative art can never be overlooked in defining the rich values and foundations of Islamic architecture. The Ateeq Mosque in Shiraz was built at the end of the Saffarid period. The construction method of these mosques is in Khorasan style, which is also called Shabestani; This method is inspired by the Prophet's Mosque in Medina, created in a rectangular space nave the direction of the Qiblah. After the extinction of the Saffarids and the coming to power of the Ilkhanids in $752 \mathrm{AH}$, the 
Khodakhaneh was built in the Azeri style in the middle of the mosque. The features of this period to use more geometry in architectural design. Simultaneously in Spain, with Abd al-Rahman II of the Umayyads in the third century $\mathrm{AH}$, the ruins were used to build the foundation.

At this time, one can observe the independent geometric style, which is known as the Emirati style, is more noticeable in the capitals and represents an endless variety of shapes. Hakam II, the son of Abdul Rahman III, officially inaugurated a new construction phase. With its magnificent structures, arches, domes, and golden mosaics that adorn the altar's facade, this architectural stage has created glory and splendor in the Grand Mosque. An example of this can be seen in the geometric designs of the altar of the Ateeq mosque of Shiraz and Cordoba mosque. These geometric patterns are by the beliefs of the people of the region. The various geometric patterns embossed in each of the two mosques are part of the semantic art, shared goals with all their differences in the Islamic world. This temporal correspondence between the two mosques and geographical, climatic, and cultural differences makes the two valuable comparative study. Much research has been conducted in the Cordoba Mosque and Shiraz Ateeq Mosque domain, but less research has been done to simultaneously examine the motifs used in these two mosques. Therefore, this article attempts to understand the two cultures and their similarities by examining the Ateeq mosque and its geometric motifs compared with Cordoba's mosque, whose origins go back to the church [3]. Therefore, in this study, first, both mosques are studied in history, then it is tried to examine the decorative motifs in them and, finally, the geometric motifs and their places of use to be compared analytically. In this way, this research attempts to convey spiritual concepts. These two buildings have undergone many changes over time, and by explaining and adapting their geometrical motifs, one can become acquainted with the place of architectural art and the spirit of artists in different eras. These dynamic and vibrant motifs associated with symbolic notions are rooted in ancient arts, and their examples can be traced back to basic geometric shapes in Islamic architecture [4]. A comparative study of the two mosques' motifs can examine Islamic culture's influence on Islamic architecture of the West and East. In this regard, the changes in Islamic culture by moving from one place to another can be demonstrated. Therefore, a comparative study between the architecture and the two mosques' motifs has particular importance from this perspective. In other words, the central question of the present study is, "what are the similarities of the designs used in different parts of Cordoba Mosque and Shiraz Ateeq Mosque?".

\section{METHODS}

This study first describes and interprets the conditions and relationships in the two mosques by descriptive method, which gives a complete definition and their differences; the social, historical, physical, climatic, and specific conditions are designed and implemented to connect the environment with space. It aims to develop a general knowledge of architectural artists, research and study all subjects that can help spread this science, and reveal its unknown causes, so this study is descriptive and analytical.

A qualitative content-based method of content analysis has also been utilized. A detailed and systematic analysis would be carried out by observing the relevant documentation and receiving the initial data of the recorded documentation and observations of the entire architecture of the said mosques. Using the qualitative method, it explores the aims and assumptions; first, the wisdom in Islamic art and the thinkers' ideas are investigated, then the shoulders and symbols in the mosques' decoration and structure in Shiraz, Iran, Cordoba, Andalusia, Spain will be discussed. In the following, the meanings of these symbols are examined by the thoughts of Islam.

\section{DISCUSSION}

\section{CONTEXTUAL APPROACH IN ISLAMI}

The meaning of context is the fundamental structure in which architecture is formed, and content and form are included. Context-oriented architecture is a phenomenon that cannot be imagined as abstract and distinct from it, not only monopolizing the potentials, being, and esoteric characteristics of the fundamentals and roots but also affecting and influencing the peripheral environment. In fact, in contextual architecture, all components are interconnected as a whole, and each component affects the whole, and any change in the components has critical effects on the whole. This style is not a science separate from culture, society, economics, and sociological classifications, but rather the echoes of thought and context. The context in which the architectural works are formed has an identity that includes, for example, physical, geographical, climatic, social, cultural, economic, and historical characteristics.

The contextual architecture emphasizes the need to pay attention to the environment around architectural work and believes that the balance between architecture and the environment can be a significant and reinforcing factor for both the work itself and the context. Contextualism is a better model for creating an environment. Therefore, more knowledge and awareness and a deeper understanding of the background and environment is necessary for architects and designers. This approach attempts to show the power of the desired visual environment on a larger scale than architecture. Landscaping is a unique feature of a place and its application in the process of design. The architectural message needs to pay attention to the physical environment around structural work [5].

The designer and architect must understand the background and context of the design and text 
and then design according to the existing conditions. The design should be based on a realistic view of environmental information, and the building should interact with its structure correctly and in a balanced way. In contextual architecture, the outcome does not work to be a space or place, but for the reproduction of environmental force and its metaphysical complement [6].

In Islamic architecture, contextual architecture is referred to as architecture that is best adapted to the environment. Islamic contextual architecture shows that a micro-scale architectural structure is affected by the building itself, the site, the context in which the building is located, and the texture and surrounding neighborhood. Studies show that Islamic designers and architects have realized their ideas based on trends that include environmental information and architectural vision and interactive interactions by understanding the context and the message and then taking into account the current situation. Contextualism is the view that considers every event as continuous as the present and ongoing history and is considered a functional and fundamental view of reality.

\section{HISTORY, CULTURE, AND RELIGION IN CONTEXTUALISM}

If a society separates itself from the past, man's efforts are considered futile, and cutting off man's historical continuity is a humiliation of his past life. We have to take advantage of what the past has done. If we want to make progress in science, we must stand on the shoulders of your veterans.

The context should also be seen as a kind of history. The context should be considered a static and time-consuming factor but a dynamic, variable, and fluid factor. In a way, the context of contextual architecture itself is variable and moving. Each building that is built is considered part of the context and as a part of the construction context after itself. The background history is about architectural buildings, the history of architectural life, and urban planning. Eliminating the historical context and not using predecessors' experiences in their attention to the context will eliminate a great advantage from the contemporary world. Loyalty to the history and culture of a land is not the preservation and repetition of past forms and their imitation, but the use of patterns and their experiences, and the creation of new forms following concepts, because architecture is the result of meaning and not form [7].

Developments in human cultures and social changes will always show their most evident and vital effects on cities and urban buildings' appearance. Therefore, architecture cannot be considered a separate science, or it can be considered a science separate from the categories of culture and religion. Because this sublime art, which has always reached us through the hands of prominent and cultured architects throughout history, hand in hand and chest to chest, has been the most beautiful manifestation and reflec tion of culture and tradition in every historical period.
The originality and identity evident in any architectural work's soul are the architects and builder's spirits, and builder in the lifeless body of a sculpture called a building. Hence, the designer pays attention to functional, technical, psychological, and aesthetic issues. It should look at other issues in a different light [8]. Issues such as culture, tradition, religion, mysticism, and philosophy, the originality and identity of each country, and the high human values must all be considered somehow.

\section{MOSQUE IN ISLAMIC CONTEXTUAL ARCHITECTURE}

Islamic art is introverted art and is the result of mystical concentration and thought, manifested in artistic activities. This art has a pure, indigenous identity and fits the spirit and social situation of its time. Islamic architecture also has a similar foundation and is closely related to decorative arts. Undoubtedly, it cannot be examined and recognized apart from the effective use of decorative arts. Islamic architecture has an inseparable connection with nature (from the perspective of contextualism), and its basis is the inseparable connection between man and nature, in tile designs, plastering, bricklaying, etc. The presence of nature is felt, and sanctity, light, enlightenment, goodness, creativity, humility, unity, and order are evident [9].

Identity is an inherent quality associated with a phenomenon that introduces part of the truth of the phenomenon. Identity means living in a world that includes both the place and the society in which one lives. Islamic architecture is a precious heritage that reflects the brilliant identity of the past. By analyzing the expression of past architecture and re-recognizing its patterns and symbols, a new expression can be achieved in the historical course so that the continuity of identity does not face problems and, based on its identical signs and patterns, can be formed.

Contextual Islamic architecture emphasizes landscaping and the connection of the environment with space, and its identity is formed by understanding the message of its context, and in fact, it conveys a message to objectivity and designs that the context of architecture (Islamic identity) has given it; The result of the building will be a small part of the surrounding nature. In contextual Islamic architecture, each building is designed and executed based on the cultural, social, historical, and physical, climatic, and specific conditions of the target geography, influenced by Islam's teachings [10]. Therefore, the Islamic building will be a member that is in harmony with the environment and a harmonious element in its bed and finally in the Islamic bed. Islamic architecture in the Islamic world is different in terms of climate, culture, and interest in geometric styles and the ideas of artists and architects in each region are different, but among the mansions that have Islamic architecture, the mosque is essential. In the Islamic world, the mosque is the center of religious life and prostration and submission. Mosques in the history of Islamic architecture have benefited from special features such as being the essential religious pillar of the Muslim community and the focal point of 
the expansion of cities and villages. Therefore, they have always had a tremendous impact on the characteristics of cognitive style, architecture, formation, and how and how to expand urban and architectural collections. Hence, this building's basic features are mainly the emergence of architecture and the most significant works of each era. Referral to these works and accurate intellectual and practical knowledge of these architects will improve the scope of our knowledge of the subject of mosque design in the past and related issues [11]. Careful study and analysis of these works are of undeniable importance in clarifying the mentioned cases. One of the first steps in achieving this goal is to know the architectural and stylistic history of this building.

The intellectual process of creating artists in designing mosques has been hidden since its inception due to many fixed and variable principles. Architects at different times and places, creating the most sacred Islamic building, manifest the fruit of their intellectual, intellectual, and practical struggle in the soil. One of the first steps in understanding mosques' architecture is to analyze existing maps and try to understand the direction of the mosque design process and the designers' strategic policies in the face of the forthcoming variables. Different or different solutions have been proposed in different places to answer different questions throughout the mosque design history.

Role of geometry in Islamic Architecture The geometric patterns of Islamic art are mainly those of the Iranian, Indian, Turkish, Arab, Greek, Spanish, and Egyptian nations, each of which had a brilliant and brilliant past in art hundreds of years before the rise of Islam. However, as Islam spread its vast lands and spread from India to Andalusia, a period of prosperity and glory emerged, and what emerged in the name of Islamic art as an aid to these nations became incredibly unique and radiant. In many Islamic arts, a duplicate unit is used to cover the surface completely. Most of these units are created with circular-based structures. The circle, the starting point, is a sign of monotheism and unity and represents eternity; it has neither a beginning nor an end. Star shapes are obtained by dividing a circle's circumference by $10,8,6,5$, or 11 points. Many examples show the role of geometry in Islamic architecture.

Geometry has a unique and privileged place in the world of tradition. As in religious sciences and education, its importance has been emphasized. According to Islamic thinkers, the sanctity of mathematics and geometry is nowhere more than art [12]. Based on this belief, in part, the matter is honored with geometry and arithmetic. Although many consider mathematics an abstract science, many civilizations have taken advantage of this feature and use mathematical knowledge to flourish their civilization. Muslims have been able to use geometry to develop their civilization in various fields. One of these areas is architecture. A place where tricks, principles, and works come together and become a factor in architecture growth. It is an excellent opportunity to give a fundamentalist identity to architecture. Geometric design, structure, decoration, and space are the unifying force of Islamic architecture. Studies in recent years on the relationship between mathematics and geometry and Islamic architecture suggest that Iranian Muslim artists have made significant advances in mathematics and geometry in the Middle Ages. Backed by this fundamentalist view, rooted in Islamic identity, geometric patterns engraved the surfaces of the building and adorned doors, walls, ceilings, and windows.

Indeed, the use of geometric arts as a basis in the composition of forms is not the exclusive privilege of Islamic art; such designs are found in almost all traditional arts, both Western and Eastern. This style is evident in the glass decorations of the Gothic-style cathedrals and the motifs of the mandala (on which the foundations of the sacred architecture of India rest). However, in Islamic art, these "spiritual geometric shapes" expand and become rational and perfected. From Muslim scholars, Islamic art has played the role of manifesting mathematical and geometric concepts. According to Farabi, these methods are identified and practiced through art [13].

\section{A BRIEF REVIEW OF CASE STUDIES}

Ateeq Grand Mosque is the oldest mosque in Shiraz, which is also called Juma Mosque or Adineh. The original building of this mosque was built in $281 \mathrm{AH}$ during the reign of Amr Laith Saffari. Later, in $752 \mathrm{AH}$, Shah Ishaq Inju built a building in the middle of the mosque, called Khodaykhaneh or Dar al-Mushaf, where the Holy Quran was kept and where it was recited. Its stone inscription is considered a useful example of calligraphy. This inscription is written in the calligraphy of Yahya al-Jamali al-Sufi, the famous calligrapher of the time of Shah Ishaq, and contains sentences in the title of the Holy Quran. This mosque is the first religious nucleus in Shiraz, which has a socio-political role and religious performance and therefore has six entrances on different sides, the most important of which is the entrance on the north side, which was rebuilt during the Safavid period [14].

It took almost two and a half centuries to build the Cordoba Grand Mosque. The old name of this mosque was "Jameh Hazrat." At the time of Abdul Rahman, the Umayyad caliph of Andalusia, the mosque had 11 porches. The mosque was built in 786 by Abdul Rahman I and became a church after the Spanish recaptured Cordoba's city. The original structure of the mosque was without arches around the courtyard. The horseshoe shape of the arches, which appeared in the Umayyad architecture from the very beginning, has dramatically expanded in Spain and North Africa. The plan of this mosque is a kind of simplified plan of the Mutawakel Mosque. Upon entering this mosque, we find ourselves amid many pillars that only lead us to the Qiblah, along with the building factions [15]. The mosque's architectural features are: wide naves, horseshoe, and congress arches, plastered decorations, Mogharnas work, and it have arches and horseshoe altars. 
This monument is best known for its large arches that resemble the Aachen Cathedral's arches in Germany. These arches are very enchanting with Islamic decorations. Also, the marble columns of Shabestan, which reach 856 cases, have given it a special effect and grandeur. Much of it is made from the remains of Roman temples or other ruined Roman buildings. Another unique feature of the Cordoba Mosque is its main entrance, which passes through the orange trees. The minaret of the Cordoba Mosque is also beautiful. This minaret's height is 20 meters, and its facade is made of marble painted with Islamic motifs. One of the notable points is that the "Damascus Grand Mosque" was inspired by its construction. The mosque also features religious changes that Cordoba has undergone throughout history [16]

\section{ANALYSIS OF GEOMETRIC MOTIFS IN THE INVESTIGATED MOSQUES}

\section{CIRCLE}

A circle, one of the most mysterious human symbols, is a reflection of the world. This geometric shape is one of the most fundamental motifs used in ancient Iranian works. The emblem symbolizes perfection, homogeneity, and the absence of frustrations. The concentric circle represents the degrees of creatures and hierarchies of creatures. For all creatures, the worldly manifestations reveal the unitary existence. The rotational movement is complete, immutable, and without start, end, and no fluctuation. The circle is a symbol of time as well because time is a continuous sequence of unchanging moments. The circle symbolizes the inscribed water. It, therefore, has a maternal principle of females. This figure also symbolizes the sky, a symbol of the universe about the earth, where the circle joins the divinity symbols, which has the desire to create life and corresponds to a rational number. In Islamic tradition, the shape of the circle is considered as the complete form. The centralized circle, without end and first radiant and complete, is the sign of absolutely. This role is the shape of the central geometric motifs of the Islamic period. The interior decoration of the dome of the mosques of the Islamic era is often a matter of solar and stellar subjects, thus indicating the late familiar relationship between the arch and heaven's dome. This mysterious symbol is also seen in the architecture and decorative motifs of Iranian art. One of the most beautiful works on which the symbols of ancient Iranian architecture are based and show geometric motifs based on the circle in Iranian architecture. An example of the circle's use as a decoration can be seen on the part of the roof of the Shiraz Ateeq Mosque (Figure 1) and the Cordoba Mosque (Figure 2) [17].

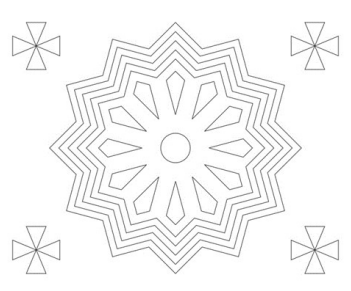

Figure 1- Redesign motifs of a circle, eight-feathered flower, and a drum-like array from the roof of Ateeq mosque

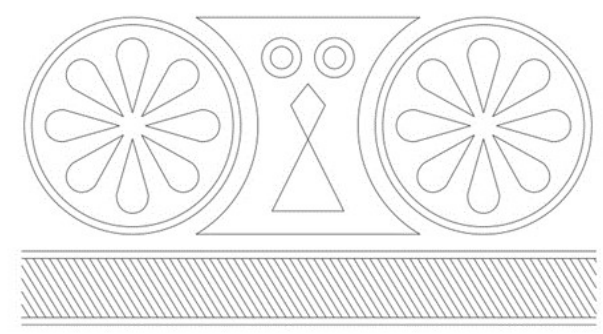

Figure 2- The redesigned circle of Shamsa's motif on the roof of the Cordoba Grand Mosque

The circle is the complete geometric shape and has played a significant role in the symbolism of all historical periods. This form expresses the totality of the human psyche in various aspects, including the relation between man and nature. In the visual arts of India and the Far East, we can see the circle's presence. In addition to the concept of perfection, the circle is a symbol of the creation of the world and the concept of time, when repeated as a series of successive moments. The circle is a symbol of the sky's continuous circular motion and is also associated with divinity. At the center of the circle, all radii tend to coincide at one point, and the integrity of these lines at this central point is at a perfect peak. In the ancient text, it is said that God is like a circle whose center is everywhere but its environment.

For Plato, the square represents the harmony that is the highest virtue, the complete knowledge through which one can attain the whole truth. The square also symbolizes place, just as the circle and spiral symbolize time. The square represents the four main directions north, south, west, and east, and so on representing the following four species:

- Four elements: water, soil, wind, fire.

- Four stages of human life: childhood, youth, middle age, old age.

- Four stages of human evolution: Embryo, life, death, resurrection.

- Four seasons: spring, summer, autumn, winter.

- Four tempers: cold, warm, dry, humid.

- Four stretches in the visual arts: vertical, horizontal, inclined, rotating.

The square is a symbol of the small world, while the circle represents the great world. In Islam, two circular and square symbols have been used most sym- 
bolically. The Kaaba, which is the Qibla of all the Muslims globally, is a black cube that the Muslims perform the Tawaf seven times around it during the rites of worship, and this Tawaf continues without interruption. In this space, the cube made of square repetition is placed in the center of the pilgrimage of the white wearing Hajjis, who must perform the Tawaf. The worship of the believers, the mosque's nave, consists of a sizeable four-chambered hall, the highest of which is a dome representing the symbol of the universe and God's greatness; In Iranian myths, squares and cubes symbolize Ahura Mazda [18].

In Islamic art, the Shamseh is inspired by the Sun's circular symbol, generally with Islamic, Khatai, inscription, geometric motifs, and in some cases, animal designs such as fish or birds. This motif is abundant in most decorative arts, whether in religious works, such as illuminating the first page of the Qoran, decorating the inside and outside of domes, mosques, etc., or in other arts bookcases, carpets, metal tools, pottery, etc. Artists have worked out the symbolic motif of Shamseh in various ways. Sometimes, it resembled the Sun with small beams or many repeating radii covering the entire surface. Occasionally inside the Sun, a human face (in female form) with intertwined eyebrows and black spots on the species has been implicated. Besides the examples mentioned above, Shamseh has been combined with other motifs such as springs, fish, lion, Simorgh, etc. As noted above, the Sun symbol (Shamseh), which is found in most Islamic art, has many symbolic meanings.

In many of their works, Muslim artists have shown the desired concept as Shamseh. Plurality in Unity and Unity in Plurality is, in fact, manifestations of the attributes and names of the essence of unity. "Plurality" has manifested itself in the form of plurality. To illustrate this concept, they have cited several examples, e.g., when we rotate the charcoal pellet with a rotating fire, the red circles result from the pellet rotation. This circle is, in fact, nothing but a manifestation of charcoal bullets at different times and places that see the dots of the trunk connected in a circle. One of the most beautiful applications of circle-based geometric decorations in art can be seen on the Cordoba Mosque (Figure 3).

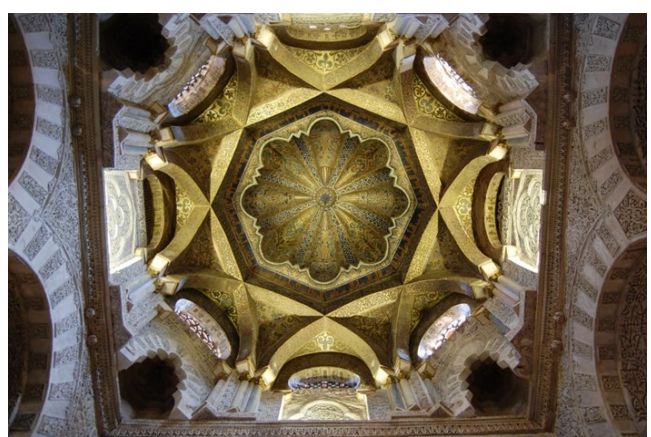

Figure 3- Inner view of dome and roof of the Cordoba Mosque

In this space, the use of the symbol of Shamseh, which was the dominant ornamental design of the mosques of Cordoba and Ateeq in the Islamic period (Figures 4 and 5), is a representation of the Sun. Shamseh in Persian literature is the source of the radiance, and the embodiment of perfection and beauty, and the high place of the Sun is the fourth constellation. Shamseh motifs are observed in the Ateeq Shiraz mosque and the Cordoba Mosque. This motif, as the name implies, evokes the concept of light. Light is widespread in all religions and primitive nations, the presence of the Sun. In ancient Spanish tribes, the Creator God united with the Sun.

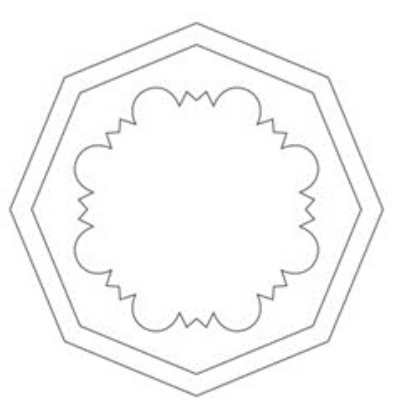

Figure 4- The redesigned symbol of the inner view of the dome of the Cordoba Mosque
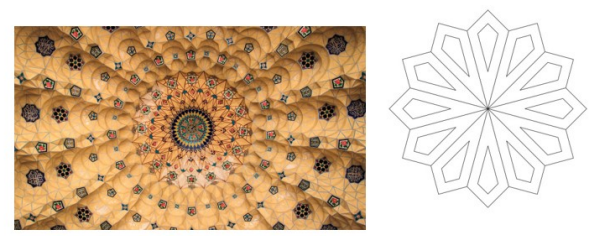

Figure 5- Main Shamsah of the inner view of the dome of the Ateeq Mosque and one of the redesigned symbol

\section{TRIANGLE}

The triangle's symbol in the downward form is the lunar apex, symbolizing the female principle, water, cold, and the physical world. The downward triangle as the Great Mother symbol is a fertile motif in the symbols of mountains and caves. The upward triangle is male, while the triangle is a symbol of triple nature, generally. In Hindu tradition also, the equilateral triangle symbolizes the male and female. If the vertex is high, the symbol is male, and if the vertex is low, the symbol is female. The combination of male and female symbols is defining the concept of thought. Figure 6 is an application of the triangle shape in the Ateeq Mosque.

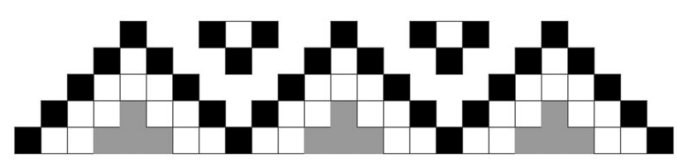

Figure 6- Triangle form of tile design in Ateeq mosque (redesign) 
CRUCIFIX

Crosses and quadrangles are among the geometrical motifs depicted in ancient Iranian art. This symbol is associated with the concept of benevolence. The crucifix symbolizes action, emergence, orbit, and permanent regeneration. There is a fundamental point about this motif; the numerical value of the Swastika is sixteen, which symbolizes the substantial progress of reality or the world. They have been known as the Sun symbol and have expressed concepts such as brightness, fertility, and happiness. In ancient times the four seasons, which signify the stages of plant life, represent the steps of the Sun passing through the four equinoxes and returning to its original place, the four stages of the moon, the lunar eclipse, the full moon, and the dark or hidden moon [19]. It was often depicted as a crucifix, which later turned into a four-arm or eight-arm Mehrani or Swastika. Wholly broken in the Islamic period, the crucifixion symbolizes the unity and embodiment of the four main directions and the angels of the four chapters, the symbol of Rome and rebirth. In the mystical literature, the crucifix is a precursor to the world of nature and glory attributes. The motifs based on geometric themes of Crucifix, Swastika, and quadrangles are multiplied in various decorative forms in the architecture of the Islamic period, which is also found in Shiraz Ateeq (Figure 7) and Cordoba mosques (Figure 8) as well.
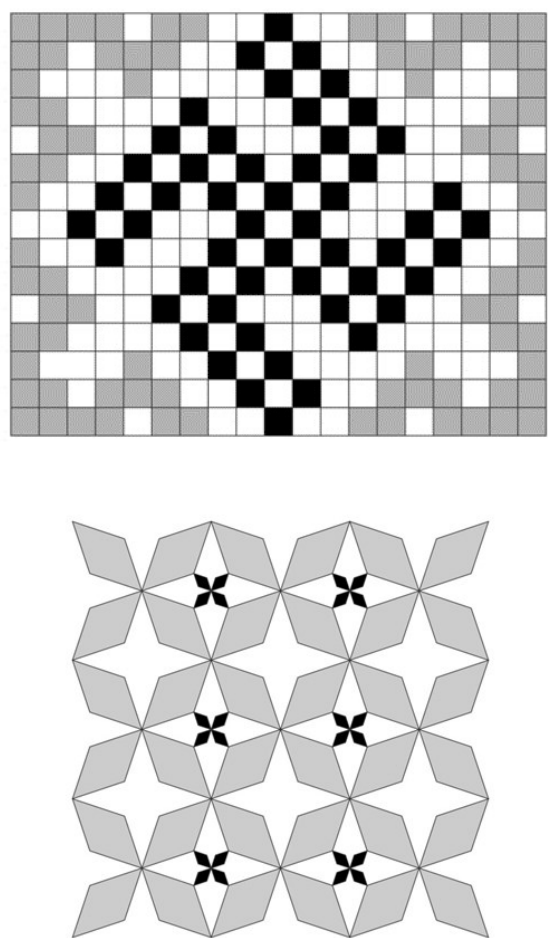

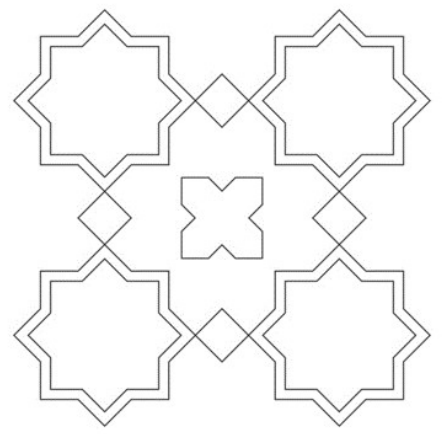

Figure 7- Different types of crucifixes in Ateeq mosque (redesigned)

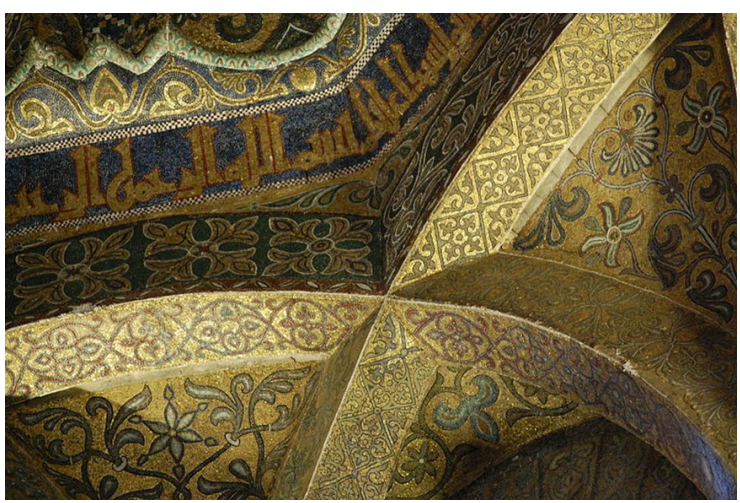

Figure 8- Crucifixes on the dome-arcs of Cordoba mosque

SPIRAL

The spiral is a complex symbol used since the Stone Age. This motif represents both the solar and lunar forces. It also symbolizes air, water, thunder and lightning, the vortex, tremendous creative power, and grace. Since it opens up, it can represent the increase and decrease of the Sun and the moon, which means continuity. The double snake symbolizes the increase or decrease of the solar or lunar forces. Like twisting and opening, it is life and death. The two snakes together represent the antithesis, which has finally come together. Their complexity is-namely time and fate, symbolized by two great forces. The snakes on Hermes cane represent the healing forces of poison, disease, and health. Also known as the symbol of protection of water, wisdom, and wealth in the llam religion, has a far-reaching role in the evil forces [20]. In llam art, the snakes were like guardians of the gates and wrapped around many tools like an ax, a cane, and a royal polo. The twisted snake's motif as a piece of rope seems to be a common one in ancient Sumerian and NewSumerian art and is then scattered over the seals and replacements of the thirteenth century $B C$. The image implies that these creatures were essentially underground and a divine source of earth's fertility. In Ilam art, two snakes form a complex column. The spirals are 
also a part of the columns of the Cordoba and Ateeq Mosques.

\section{INTERVENTION WAVE}

The motif of the wave geometrical theme is one of the widely used drawings in Islamic art and architecture. The tide of intervention in Islamic art symbolizes the seven heavens. This visual element has not been observed in the investigations between the Islamic artifacts and the Jiroft archaeological site artifacts. However, the existence of a similar wave motif among the goddess temple paintings in Turkey's Hivokuk castle of the 6 th millennium BC shows that this sign's geometric form has been known since ancient times. This motif is its mirror form and has been used in both mosques in Cordoba and Shiraz. Figures 9 and 10 illustrate these motifs in two mosques.
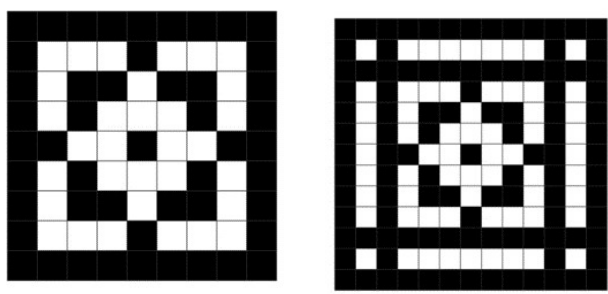

Figure 10- Redesign of intervention wave motifs from Cordoba Mosque

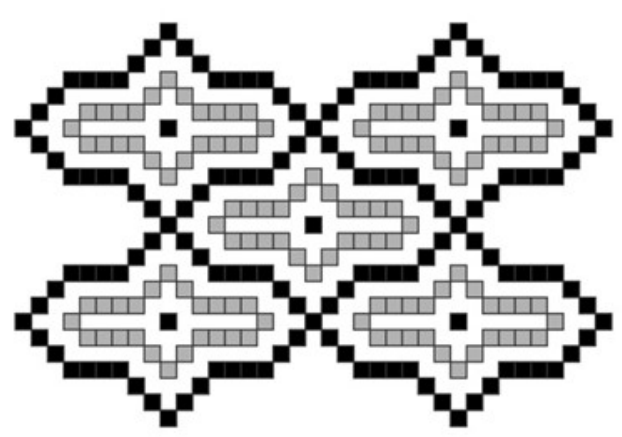

Figure 10- Figure 10- Redesign of intervention wave motifs from Ateeq Mosque

\section{STAR}

The star symbolizes divinity, transcendence, eternity, immortality, and hope. It is also known as the sign of the king of heaven's ladies who have a crown of stars. In Mesopotamia, the star badge was used as a sign of devotion. The four-pointed star that later became a crucifix was a non-iconic figure of the Sun God, love, and justice. The upper outline of the star represents light and spirituality. Figures 11 and 12 illustrate the star's motifs in the two mosques, Ateeq Shiraz and Cordoba. According to the study's findings, most of the star motifs used in the Ateeq Mosque have been worked as eight-pointed stars. The eight-pointed star is one of the motifs found on the fifth and sixth centuries' inscriptions, later known as rosette flowers in Islamic art. The eight-pointed star has somehow evolved into a circular role, and later a crucifix and a star. In other words, the symbol of the Sun has been created in different ways in different periods and in art, each of which has different meanings [21].

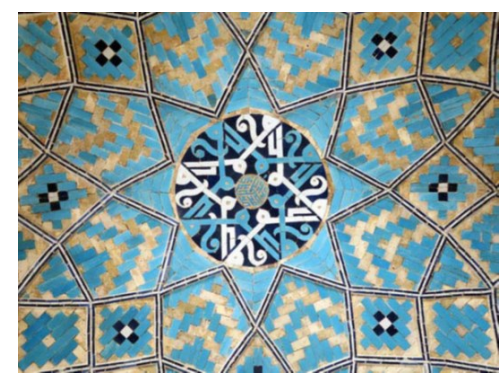

Figure 11- Stat motif of Ateeq Mosque

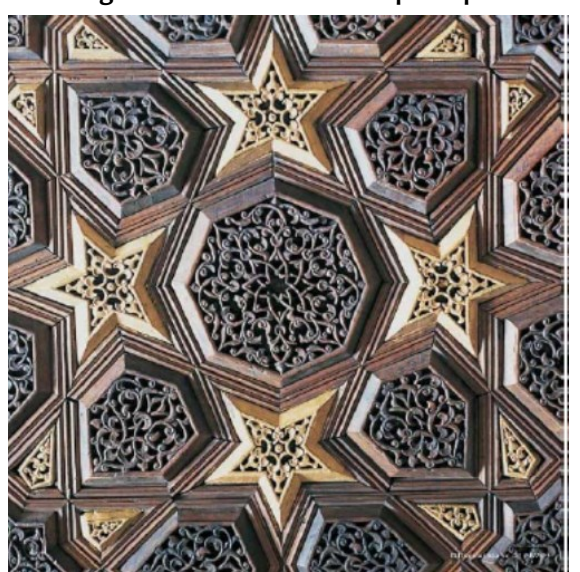

Figure 12-Star motif of Cordoba Mosque

The eight-pointed star-shaped by the rotation of two squares has emerged and has long been considered the number eight, the Sun's number throughout Europe, Asia, and Africa, as expressed in Islam's Eight Heaven and Eight Doors in different forms. Paradise, in the mysticism of the eighth door, is considered repentance and always open. However, the star motif in the Cordoba Mosque is a five-pointed star. The number five is usually related to human life and the five senses. This number also plays a role in general astronomical processes [22]. The number five is also significant in the Islamic tradition. In addition to the five pillars of religion, Muslims have five daily prayers. The Islamic precepts of martyrdom, prayer, fasting, zakat, hajj, obligatory, mutabah, mahabah, maqrawah, and haram are five categories. In the trophy war, five parts are to be paid for Khums (one-fifth). Thus, it can be stated that the five feathered stars in the Cordoba Mosque refer to the pillar and the commandments of religion.

DRUMS

Dormant drums and rotating drums are also used in decorating Islamic architecture. This motif in Islamic architecture refers to the bloated form and 
resurrection. Among the motifs discovered in Susa's ancient site belonging to llam civilization, this arrangement is dormant and orderly. This role is evident in most Islamic architectures, as exemplified in the two mosques of Cordoba and the Ateeq Mosque in Figures 13 and 14 [23].

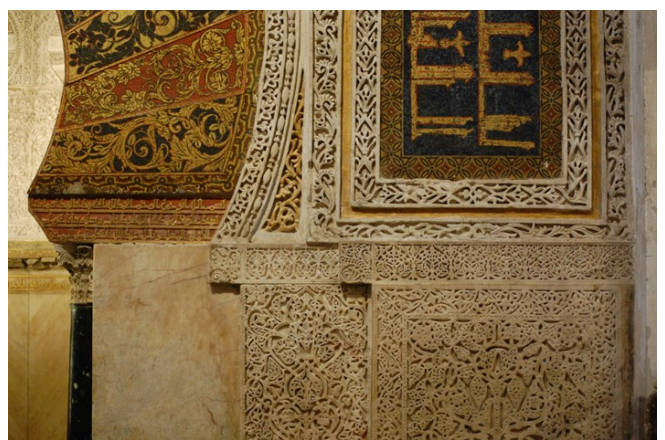

Figure 13- Different drum motifs of the Cordoba Mosque

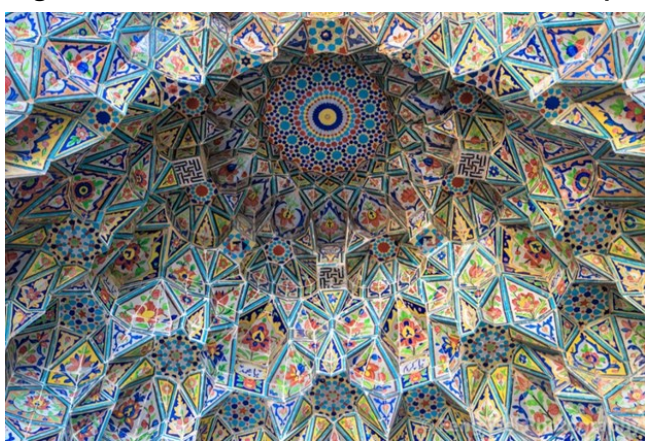

Figure 14- Drum like motifs of Atiq mosque

\section{CONCLUSION}

The present study's main question was: What are the similarities of the designs used in different parts of the Cordoba Mosque and Shiraz Ateeq Mosque? According to the present analysis findings, examples of geometric motifs can be found in the comprehensive mosques of Antiquarian and Cordoba. Symbolic geometric motifs represent natural elements. The circle symbolizes the universe and the holy and Godly symbol, the symbol of the Sun and the celestial light, the triangle with the downward symbol of the female principle, and the upward symbol of the mountain and the male. Finally, the repeating triangles with the upward and downward triangles symbolize the unity of opposing elements. The crucifix symbolizes the rotation of the seasons and the permanent and spiral reproduction symbolizes fertility. In the Islamic period, these motifs are decorated within architectural spaces. In ancient Iranian architecture, geometric motifs represent natural elements and human existence, and life dependence on nature. Thus, as the praise and sanctification of natural elements were considered, geometric symbols were symbolically evocative of those sacred elements and illustrated in Iran and Spain's arts.

The contextualist approach emphasizes geometrical and environmental linkage with space, shap- ing the context of its contextual message and objectifying and designing the contextual context that the context has given it; this study's subject is based on religious thoughts. Most of the motifs in this study are religious symbols. Crucifix refers to unity, and unity is one of the most critical issues in Islam's religion. On the other hand, the symbol refers to the four seasons that are seen objectively in nature. The circle symbolizes the Sun, which is also in the context of natural motifs. The inside wave refers to the seven heavens, which have been repeatedly mentioned in Islam. Drum refers to the Day of Judgment, which is one of the essential pillars of Islam. Therefore, it can be concluded that the motifs expressed refer to religious and natural contexts.

It can be concluded that in the Islamic period, Iranian architecture is one of the fields of the emergence of beautiful and unique geometric designs. Examination of the relics found in Islamic mosques shows that they are all decorated with geometric motifs. The artifacts from both show circular motifs, crucifixes and triangles, and other geometric motifs in decorating the building. Thus circle analysis, symbolizing divinity and sacred symbols, and symbolizing the Sun and celestial illumination, had a unique role in ancient art and architecture. Since the divine and holy symbols are associated with the attribute of blessing, so the application of this geometrical symbol can be related to the concept of blessings and excess. In Hindu tradition, the equilateral triangle symbolizes the sex of men and women. Crosses and quadrangles are among the geometrical motifs depicted in ancient art. This symbol is associated with the concept of benevolence. The crucifix symbolizes action, emergence, orbit, and permanent regeneration, and there is a fundamental point about this motif. The spiral is a complex symbol, representing both the solar and lunar forces. It also symbolizes air, water, thunder and lightning, the vortex, tremendous creative power, and grace. Geometric multifaceted shapes are mystical motifs used in ancient Islamic art. These shapes, which are always associated with the five, six, eight, and so on numbers, are based on the circle's divisions. These cosmic motifs are considered as symbols that represent human thinking about the basic structure of the universe.

\section{REFERENCES}

[1] Y. Gruter, Aesthetic in Architecture. Tehran: Shahid Beheshti University, 1996.

[2] R. A. Maleki, "Forms and Symbolic Roles in Iranian Mosques," A Publication Dedicated to the Immortal Legacy, vol. 6, no. 22, pp. 110-116, 1998.

[3] J. F. Bonner, "No TitleThe Historical Significance of the Geometric Designs in the Northeast Dome Chamber of the Friday Mosque at Isfahan," Nexus Network Journal, vol. 18, pp. 55-103, 2016. 
[4] M. R. Ismoail, "A Parametric Investigation of the Acoustical Performance of Contemporary Mosques," Frontiers of Architectural Research, vol. 2, no. 1, pp. 30-41, 2013.

[5] M. Masoud and H. R. B. Shahraki, Infill Buildings in the Historical Context, the Principles of Design, and Evaluation Criteria. Tehran: Azarakhsh Publication, 2012.

[6] S. Blair and J. Bloom, Islamic Mongols: From the Mongol Invasions to the llkhanids, in Islamic Art and Architecture. Ullmann Press, 2007.

[7] C. Kerenyi, Dionyos: Archetypal Image of Indestructible Life. New Jersey: Princeton University press, 1976.

[8] G. Çizgen, "Rethinking The Role of Context and Contextualism in Architecture and Design," Eastern Mediterranean University (EMU), 2012.

[9] B. . Brolin, Field-Oriented Architecture. Esfahan: Khakh Publication, 2004.

[10] B. Ghadiri, New Structures in Historical Contexts. Tehran: Cultural Research Office, 2006.

[11] M. K. 'Alī, The Past of al-Andalus and Its Present. Egypt: Al-Maktaba al-Ahliyya, 1923.

[12] M. Yousefi Kiani, History of Art and Architecture in the Islamic Period. Tehran, 1995.

[13] Y. Abdullahi and M. R. BinEmbi, "Evolution of Islamic Geometric Patterns," Frontiers of Architectural Research, vol. 2, no. 2, pp. 243-251, 2013.

[14] M. Makinejad, History of Iranian Art in the Islamic Architectural Decorations. Tehran: Center for Research and Human Development, 2008.
[15] L. A. Janet, "The Islamic City-Historic Myth, Islamic Essence, and Contemporary Relevance," International Journal Middle East Stud, vol. 19, no. 2, pp. 155-176, 1987.

[16] Y. Bani-Yassen, "The Image of al-Andalus in Oriental Geography During the Centuries," hijrī four first Al-Majala al-'Arabìya li-l-'Ulūm alInsānìya, vol. 34, no. 134, pp. 11-40, 2016.

[17] J. Hall, Dictionary of Graphical Symbols in the East and the West. Tehran: Contemporary Culture, 2001.

[18] M. Khazaei, One Thousand Nagsh. Tehran: Islamic art studies publication, 2002.

[19] G. Memarian, Iranian Architecture. Tehran: Knowledge Soroush Publications, 2008.

[20] M. Nagizadeh, "The Basis of Religious Art in Islamic Culture," Cazi University, 2005.

[21] R. E. K. I. Mahina and S. A. Selcuk, "Evolution of Geometric Patterns in Islamic World and A Case on The Jalis of The Naulakha Pavilion in The Lahore Fort," Journal of Science Part B: Art Humanities Design and Planning, vol. 6, no. 2, pp. 83-97, 2018.

[22] M. A. Hanifi and A. Maleki, "Comparative Analysis Of The Decorated Arraies With Geometric And Plant Motifs In Architecture Of The Grand Mosque Of Yazd And Their Developments," The Turkish Online Journal of Design Art and Communication, vol. 6, no. 196-216, 2016.

[23] N. Ismail and F. N. Hamdan, "Islamic Geometric Pattern Design Of State Mosque In Malaysia," in 8th UPI-UPSI International Conference 2018 (UPI-UPSI 2018), 2019, pp. 74-75. 